\title{
Assimilation of Interorganizational Business Process Standards
}

\author{
Hillol Bala, Viswanath Venkatesh \\ Walton College of Business, University of Arkansas, Fayetteville, Arkansas 72701 \\ \{hbala@walton.uark.edu, vvenkatesh@vvenkatesh.us\}
}

\begin{abstract}
$\mathrm{O}^{\mathrm{r}}$ ganizations have not fully realized the benefits of interorganizational relationships (IORs) due to the lack of cross-enterprise process integration capabilities. Recently, interorganizational business process standards (IBPS) enabled by information technology (IT) have been suggested as a solution to help organizations overcome this problem. Drawing on three theoretical perspectives, i.e., the relational view of the firm, institutional theory, and organizational inertia theory, we propose three mechanisms—relational, influence, and inertial-to explain the assimilation of IBPS in organizations. We theorize that these mechanisms will have differential effects on the assimilation of IBPS in dominant and nondominant firms. Using a cross-case analysis based on data from 11 firms in the high-tech industry, we found evidence to support our propositions that relational depth, relationship extendability, and normative pressure were important for dominant firms while relational specificity and influence mechanisms (coercive, mimetic, and normative pressures) were important for nondominant firms. Inertial mechanisms, i.e., ability and willingness to overcome resource and routine rigidities, were important for both dominant and nondominant firms.
\end{abstract}

Key words: interorganizational relationships; business process; process standards; firm dominance; assimilation; deployment; relational view of the firm; institutional influences; organizational inertia; interorganizational system

History: Robert Zmud, Senior Editor. This paper was received on August 22, 2005, and was with the authors 10 months for 5 revisions.

\section{Introduction}

In today's economy characterized by global networks of firms, successful interorganizational relationships (IORs) are critical for firm performance (Barringer and Harrison 2000). While information technologies (ITs) enhance organizational abilities to develop and maintain digitally-enabled IOR, (Barua et al. 2004, Rai et al. 2006), many firms fail to realize the benefits of such digitization because of the lack of integrated and coordinated interorganizational business processes (Chabrow and Sullivan 2004). For example, in the retail industry, $3.5 \%$ of sales-about $\$ 40$ billion annually-are lost because of inadequate or lack of interorganizational business process integration and automation (Sullivan 2004). More than $60 \%$ of firms in the United States across different industries conduct business-to-business transactions through manual processes and disconnected IT systems (Wailgum 2006). Recently, IT-enabled interorganizational business process standards (IBPS)—open specifications for integrating and automating collaborative business processes using ITs-have been suggested as a solution to improve IORs (Gosain et al. 2003, Markus et al. 2006). Despite demonstrated gains, IBPS use is still limited (Wailgum 2006).

While there is a rich body of work on IT-enabled IOR, there is little empirical research on IBPS in the context of IORs. Prior information systems research on IORs falls into two broad streams: (1) adoption, use, and value of interorganizational systems (IOS) such as electronic data interchange (EDI) in IORs; and (2) IT-enabled interorganizational governance and configuration issues and subsequent firm performance. Research in the first stream has suggested various determinants of adoption and use of IOS such as trust, buyer and supplier power, transaction-specific investments, reciprocal investments, information processing needs, institutional pressures, network externalities, technology readiness, and instrumental benefits (e.g., Chwelos et al. 2001, Mukhopadhyay 
et al. 1995, Premkumar et al. 1994, Teo et al. 2003). Research in the second stream has suggested different governance mechanisms and configuration modes for IORs (e.g., Bensaou 1999, Choudhury 1997, Malhotra et al. 2005, Subramani 2004) and has also focused on the distinct role of IT infrastructure and interorganizational process integration capability as a source of firm performance (e.g., Barua et al. 2004, Rai et al. 2006, Sambamurthy et al. 2003). Research focused on IBPS is important as these standards are believed to be the next step in making interorganizational processes highly efficient, leveraging relationships, and enhancing firm performance (Markus et al. 2006).

The objective of our work is to understand the assimilation of IBPS in dominant and nondominant firms in the context of IORs. Firm dominance in this context refers to the extent to which a firm is dominant over its trading partner in an IOR (see \$3.2 for more details). Barringer and Harrison (2000, p. 395) noted that because "none of the theories of interorganizational relationship formation is complete by itself, there is need for consideration of multiple perspectives as new theories are developed and tested." In keeping with this, we present a richer understanding of the mechanisms of IBPS assimilation by drawing on and integrating multiple theoretical perspectives. Specifically, drawing on three theoretical perspectives, i.e., the relational view of the firm (e.g., Dyer and Singh 1998), institutional theory (e.g., DiMaggio and Powell 1983), and organizational inertia theory (e.g., Tushman and O'Reilly 1996), we suggest that three key mechanisms-relational, influence, and inertialwill influence the assimilation of IBPS. This research will deepen understanding of IOS implementation by highlighting the differential influences of these mechanisms at various stages of IBPS assimilation in dominant and nondominant firms.

\section{Interorganizational Business Process Standards (IBPS)}

Interorganizational business processes are a set of interrelated and sequential activities that are shared and executed by two or more trading entities to achieve a business objective that is of value to the trading partners. A standard is a set of "technical specifications adhered to by a producer, either tacitly or as a result of a formal agreement" (David and Greenstein
1990, p. 4). Drawing on these definitions, we define IBPS as technical specifications for interrelated, sequential tasks and business documents that are agreed upon and shared by trading entities to achieve a defined and common business objective. IBPS are designed and developed to automate, integrate, and facilitate value chain activities such as supply chain management, collaborative forecasting, new product development, and inventory management. These standards are typically developed by consortia of firms and are also known as vertical information systems (VIS) standards as they promote coordination among the firms within (or across) vertical industry sectors (Markus et al. 2006, Nelson et al. 2005, Wigand et al. 2005, Zhao et al. 2005). For example, RosettaNet's Partner Interface Processes (PIPs) is a VIS standard for the semiconductor and electronic components industry. In this paper, we use the term IBPS to refer to standards within an industry vertical.

IBPS are semantic standards that not only specify and define the structure and format of business messages through a common language but also orchestrate the message exchange choreography, i.e., sequence of steps required to execute an atomic business process among trading partners. The presence of such business process content and choreography differentiates IBPS from IOS standards such as ANSI X.12 that specify a common, uniform language for data exchange and communication protocols among trading entities (Zhu et al. 2006). In addition to business process choreography, IBPS specify transfer, routing and security protocols, and implementation frameworks. It is important to note that IBPS are standards only for public processes that involve interactions among the trading partners (e.g., exchange of business messages). Firm-specific private processes (e.g., interaction with internal back-end systems and processes) are typically beyond the scope of IBPS (Cartwright et al. 2005) and the discussion in this paper.

\section{Theory Development}

Theory development begins with a discussion of different stages of IBPS assimilation and follow with a discussion of firm dominance wherein we focus on how dominant and nondominant firms differ in terms of assimilating innovations in their value chains. We 
then present the three theoretical perspectives that we draw from, followed by our conceptual model and propositions.

\subsection{Assimilation of IBPS}

Assimilation of IBPS is defined as the degree to which IBPS support and enable relevant business activities in the value chain and become widely deployed and routinized in organizations (see Fichman and Kemerer 1997, Purvis et al. 2001). Assimilation is the extent to which a firm has progressed through stages of innovation deployment-from initial awareness and adoption to general deployment or routinization (Fichman 2001). There is a clear distinction between adoption (or acquisition) of an innovation and its degree of deployment or routinization. A firm may adopt an innovation but fail to routinize it due to various technological, organizational, and environmental factors (Fichman and Kemerer 1999). This suggests that the antecedents and mechanisms of innovation deployment can be different from the drivers of innovation adoption. In addition, the nature of the innovation is likely to play a role as assimilation may unfold differently for different innovations (Zmud 1984). Consistent with prior research (e.g., Fichman and Kemerer 1997), we conceptualize four distinct stages of IBPS assimilation: awareness, adoption (or rejection), limited deployment, and general deployment (see Table 1). While awareness is an important stage, in this research we primarily focus on the subsequent stages (i.e., adoption or rejection, limited deployment, and general deployment) because of their practical and theoretical importance.

\subsection{Dominant vs. Nondominant Firms}

Firm dominance is an important determinant of firm behavior in developing and assimilating various organizational innovations, such as new product development and implementation of new technologies (Chandy et al. 2003, Sorescu et al. 2003). Dominant firms, for example, typically have greater resources that catalyze their ability to invest in innovations (Nohria and Gulati 1996). At the same time, these firms may have greater inertia (i.e., willingness to maintain status quo-current market share and profits) that may inhibit their motivation to invest in innovations that can potentially disrupt their existing practices or routines (Tushman and O'Reilly 1996). We conceptualize firm dominance at the IOR level-i.e., the degree to which a focal firm is dominant over its trading partner in a given IOR (e.g., a supply chain relationship). In a typical IOR, there are power differences between partners for several reasons-e.g., assets, investments, market share differences, profits, and resource and revenue dependencies (Chandy et al. 2003, Corsten and Kumar 2005, Sorescu et al. 2003). Prior research on IOS adoption (e.g., Riggins et al. 1994, Webster 1995) and relationship marketing (e.g., Jap and Ganesan 2000) has suggested that dominant partners often require nondominant partners to make significant relation-specific investments (e.g., IOS implementation) to improve interorganizational coordination. The literature on standards suggests that standards development tends to be controlled by dominant firms that often impose their own standards on their nondominant counterparts (David and Steinmueller 1994, Jacobs 2000). Even standards

\section{Table 1 Assimilation Stages of IBPS}

\begin{tabular}{|c|c|c|}
\hline Assimilation stages & Description & Example \\
\hline Awareness & $\begin{array}{l}\text { Key decision makers are aware (e.g., initial understanding, familiarity, } \\
\text { and consideration) of IBPS. Formal evaluation and trial may be initiated } \\
\text { in-house or through vendor organizations. }\end{array}$ & $\begin{array}{l}\text { Key decision makers know about IBPS developed and } \\
\text { promoted by industry consortia such as RosettaNet, } \\
\text { MISMO, PapiNet, CIDX, and Supply Chain Council. }\end{array}$ \\
\hline Adoption (or rejection) & $\begin{array}{l}\text { Key decision makers make the adoption or nonadoption decision based on } \\
\text { their understanding of the potential costs and benefits of IBPS. }\end{array}$ & $\begin{array}{l}\text { Key decision makers may decide to adopt certain } \\
\text { IBPS to change their interorganizational processes. }\end{array}$ \\
\hline Limited deployment & $\begin{array}{l}\text { The organization implements a few IBPS that relate to certain } \\
\text { portions of its interorganizational exchanges with at least one } \\
\text { of its trading partners. }\end{array}$ & $\begin{array}{l}\text { An organization may implement an IBPS to } \\
\text { standardize how it handles requests for price and } \\
\text { availability of its products. }\end{array}$ \\
\hline General deployment & $\begin{array}{l}\text { The organization implements a set of IBPS that allows it to conduct a } \\
\text { complete interorganizational exchange with at least one of its } \\
\text { trading partners. }\end{array}$ & $\begin{array}{l}\text { An organization may implement a set of related } \\
\text { IBPS to standardize its entire order management } \\
\text { (e.g., order-to-cash) process. }\end{array}$ \\
\hline
\end{tabular}


development consortia, such as RosettaNet, are led by a group of dominant firms in their respective industries (Jacobs 2000). For these reasons, we expect that the assimilation of IBPS in the context of IORs will unfold differently for dominant versus nondominant firms.

\subsection{Theoretical Perspectives}

We draw from three theoretical perspectives to understand IBPS assimilation in dominant and nondominant firms-the relational view of the firm (e.g., Dyer and Singh 1998), institutional theory (e.g., DiMaggio and Powell 1983), and organizational inertia (Tushman and O'Reilly 1996). Three key characteristics of IBPS drive selection of these perspectives. First, IBPS are essentially specifications for creating, sustaining, and extending relationships among trading partners. Therefore, adoption and deployment of IBPS by a focal firm do not yield any benefit unless the same IBPS are adopted and deployed by at least one of its trading partners-hence, mutual and synergistic assimilation is important. The relational view of the firm and institutional theory perspectives are expected to shed light on this interorganizational nature of IBPS assimilation. Second, deployment of IBPS is resource intensive (i.e., hardware, software, and human capital) due to the complexity of the implementation and integration requirements (Cartwright et al. 2005). Further, implementation of IBPS requires substantial changes to organizational routines to be compliant with the standards specifications (Cartwright et al. 2005). Many firms are reluctant to make such changes, contemplating a loss of power and control over their portion of the interorganizational processes (Porter 2001). Organizational inertia perspectives are expected to enhance understanding of this resource intensity and the routine change aspects of IBPS assimilation.

3.3.1. Relational View of the Firm. The relational view of the firm (Dyer and Singh 1998) suggests four sources of relational rents (i.e., performance gains from IORs): (1) relation-specific assets; (2) interorganizational routines for knowledge sharing; (3) effective governance mechanisms; and (4) exploitation of complementary capabilities. We suggest that these four sources create relational specificity, defined as the degree to which a firm develops and is willing to sustain a unique relationship with a particular trading partner (Madhok and Tallman 1998). We expect that if assimilation of IBPS is perceived to threaten existing relational specificity, it is more likely that firms will not assimilate IBPS and vice versa. IBPS may reduce relational specificity of a focal firm in at least two ways: (1) if important trading partners of the focal firm do not adopt the same IBPS; and (2) if many other firms adopt the same IBPS. In some cases, IBPS can increase relational specificity, at least in the short term, for a focal firm if important trading partners standardize the same interorganizational processes, thus creating interorganizational asset interconnectedness (Dyer and Singh 1998).

We extend the relational view of the firm by suggesting two additional mechanisms pertinent to IBPS that can generate relational rents: relational depth and relationship extendability. We define relational depth as the degree to which a firm finds new avenues to collaborate with existing partners. A firm may increase relational depth with trading partners by sharing additional data within an existing interorganizational process or by collaborating in other activities in the value chain, e.g., new product development processes. IBPS can improve relational depth in several ways: (1) improving coordination by streamlining processes (Gosain et al. 2003); (2) improving interorganizational knowledge sharing routines, i.e., knowledge richness (Malhotra et al. 2005, Sambamurthy et al. 2003); and (3) increasing the depth of collaboration by allowing firms to standardize more processes, thus improving collaborative flexibility and multienterprise visibility (Damodaran 2005).

Firms often look to redeploy and use a relationspecific asset (e.g., an EDI system) or routine (e.g., sharing best practices with a partner) in other relationships or to develop new relationships to increase the breadth of collaboration (Bensaou and Anderson 1999, Rokkan et al. 2003). IBPS has "plug-and-play capabilities" to dynamically extend IORs, without additional investments, to new or existing partners who have already deployed the similar IBPS (Gosain et al. 2003, p. 190). We conceptualize this capability as relationship extendability, defined as the degree to which a firm can redeploy and leverage existing relation-specific assets and routines in other relationships, i.e., a firm's ability to reconfigure existing competencies for new IORs (Teece et al. 1997). Exploiting such competencies as part of the business 
model is key to enhanced firm performance (Levinthal and March 1993). ${ }^{1}$ Relationship extendability can lead to cost effectiveness, high partner density (i.e., number of partners), partnering flexibility (i.e., ease of changing partners), partnering agility (i.e., ability to leverage partners' resources), greater structural embeddedness (i.e., ability to go beyond the immediate ties of firms), greater control over partners, and less resource dependency on partners (Gosain et al. 2004-2005, Gulati 1998, Sambamurthy et al. 2003).

3.3.2. Institutional Theory. Institutional theory (e.g., DiMaggio and Powell 1983) suggests three influence mechanisms of institutional isomorphism-the process of gaining political and institutional legitimacy and market positions: coercive, mimetic, and normative. These influence mechanisms force organizations to conform to norms, traditions, and social expectations in an institutional environment and expedite the process of homogenization at the interorganizational level (Oliver 1991, 1997). Coercive isomorphism is driven by two key forces: pressure from other firms on which a focal firm is dependent and pressure to conform to societal expectations (DiMaggio and Powell 1983). Mimetic isomorphism is a response to uncertainty wherein managers mimic a successful peer. Normative isomorphism occurs for two reasons: (1) due to their similar professional training, managers develop a shared mental model of the institutional environment and act accordingly; and (2) managers interact with each other through professional and trade professional and trade associations and form perceptions of industry norms and expectations (DiMaggio and Powell 1983). Drawing on and extending the work of Teo et al. (2003) who studied the role of these mechanisms in IOS (e.g., EDI) adoption contexts, we suggest that these mechanisms will play a differential but important role at different stages of IBPS assimilation in dominant and nondominant firms.

3.3.3. Organizational Inertia Theory. Organizational inertia refers to a focal firm's "inability to enact internal change in the face of a significant external

\footnotetext{
${ }^{1}$ A business model describes a method of doing business (i.e., what a firm does and how it makes money doing it) by which a firm can sustain itself (see Magretta 2002). In recent years, many firms (e.g., Cisco, Intel) have incorporated the use of IBPS into their business models.
}

change" (Gilbert 2005, p. 741). Such an inability to act in the presence of a significant threat or opportunity such as technological or regulatory changes is a major source of organizational failure (Henderson and Clark 1990, Levinthal 1992). Gilbert (2005) classified the structure of inertia into two distinct categories: resource and routine rigidities. Resource and routine rigidities are a firm's inability or failure to change resource investment patterns and organizational processes respectively in response to external threats or opportunities (Gilbert 2005). We suggest that if a firm does not have the ability and/or willingness to overcome resource and routine rigidities, it is unlikely to adopt and deploy IBPS.

Overcoming resource rigidity in the context of IBPS assimilation requires top management support, technological capability and readiness, and the ability to mobilize resources, i.e., financial and/or human capital (Cartwright et al. 2005). Easily recoverable and redeployable slack resources can also help overcome resource rigidity (Nohria and Gulati 1996). Routine rigidity, which captures the cultural and political aspects of a firm, can be more difficult to overcome (Tushman and O'Reilly 1996). Organizational routine refers to the repeated patterns of behavior bound by rules and customs that characterize an organization's ongoing activity (Feldman and Pentland 2003). Routine rigidity results when organizational routines become self-enforcing, nonadaptable, tightly embedded in the environment, and, therefore, difficult to change (Nelson and Winter 1982, Teece et al. 1997). As noted earlier, IBPS implementation calls for a firm to change its interorganizational routines, i.e., stable patterns of interactions between two firms (Zollo et al. 2002). Managers may feel that changing to externally developed IBPS will cause a major disruption in existing routines that are embedded in the organization's values and culture (Nelson and Winter 1982) and may also result in a loss of control and power over their interorganizational processes (Porter 2001).

\subsection{Conceptual Model and Propositions}

Drawing on the three theoretical perspectives described in $\S 3.3$, we develop our model of IBPS assimilation, shown in Figure 1. We posit that relational mechanisms (i.e., relational specificity, relational depth, and relationship extendability), influence mechanisms 
Figure 1 A Conceptual Model of IBPS Assimilation

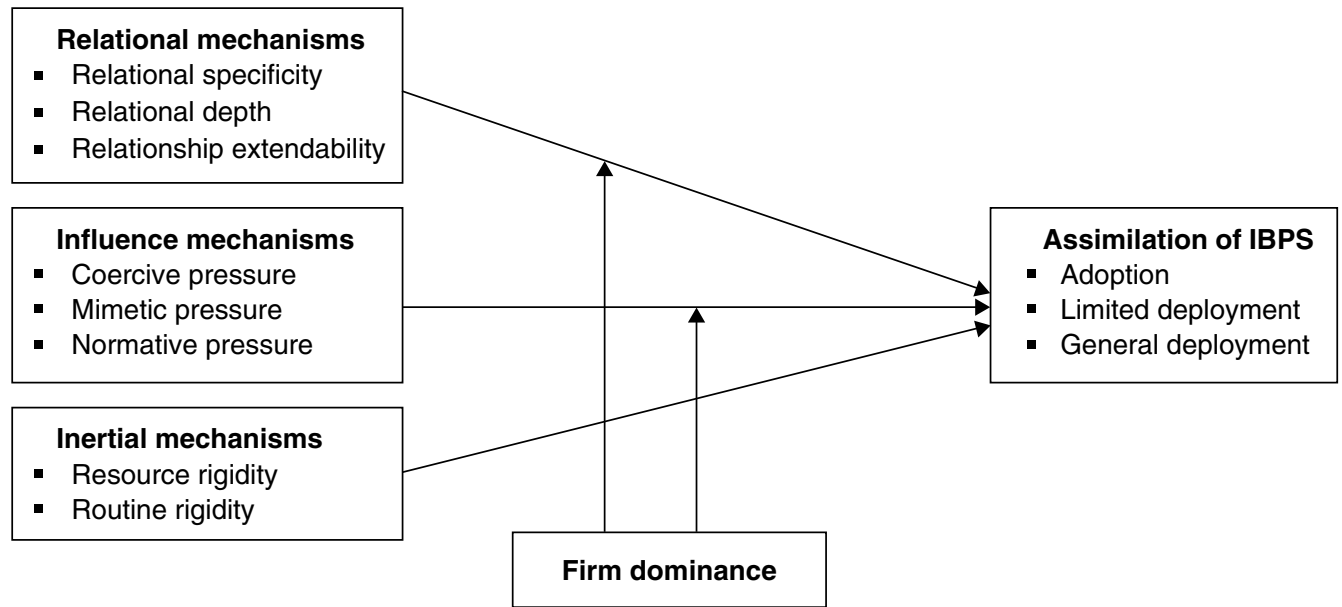

(i.e., coercive, mimetic, and normative pressures), and inertial mechanisms (i.e., resource and routine rigidities) will play important roles in IBPS assimilation (i.e., adoption, limited deployment, and general deployment). We also posit that the role of these mechanisms will be different for dominant versus nondominant firms except for inertial mechanisms that will exert a similar influence on IBPS assimilation for both dominant and nondominant firms. In this section, we develop propositions to delineate the relationships shown in the conceptual model.

3.4.1. Relational Mechanisms. Because of their greater market share and/or resources, dominant firms typically do not depend on a specific trading partner for resources and revenues (Pfeffer and Salancik 1978). Therefore, relational specificity (i.e., willingness to sustain a unique relationship with a particular trading partner) is not a major motivation for dominant firms to invest in IBPS and change their existing interorganizational routines (Jap and Ganesan 2000). However, these firms are more likely to be interested in cost savings and process efficiencies gained through relational depth (e.g., improved coordination, greater knowledge sharing, and collaboration) and relationship extendability, e.g., partnering flexibility or ability to change trading partner (Gosain et al. 2004-2005). Dominant firms may have trading partners who do not have the ability to process transactions in a timely manner and provide accurate and timely transaction-related information (Jap and Ganesan 2000). Decision makers in dominant firms may perceive that IBPS will resolve this apparent capability mismatch. Such instrumental benefits of IBPS will act as an incentive for dominant firms to commit resources to IBPS implementation and incorporate the use of IBPS in their business models (Magretta 2002). For example, as noted earlier, many dominant firms (e.g., Intel and Cisco) have incorporated IBPS in their business models to improve value chain coordination, collaboration, and knowledge sharing with their partners, (i.e., relational depth) and to expand their partner base, (i.e., relationship extendability) (Karpinski 2001, Whiting 2003). Therefore, we suggest:

Proposition 1 (P1). Dominant firms are likely to have a greater assimilation of IBPS if IBPS are perceived to improve relational depth $(\mathrm{P} 1 \mathrm{a})$ and provide relationship extendability (P1b).

Nondominant firms typically depend on a few dominant trading partners for a majority of their revenues (Hart and Saunders 1997). For these firms, the key relational mechanisms to assimilate IBPS are relational specificity, i.e., the ability to sustain existing relationships, and relationship extendability, i.e., the ability to redeploy IBPS in other relationships, particularly with dominant firms that have already adopted and deployed the same IBPS. If other important trading partners adopt and deploy IBPS, nondominant firms will be motivated to do the same to sustain the relationship that is a source of resource and revenue (Jap and Ganesan 2000). Further, IBPS 
may help nondominant firms create new relationships or enhance existing relationships (i.e., relationship extendability) through push and pull mechanisms: (1) Nondominant firms may find other firms that implemented the same IBPS and develop relationships with these firms, i.e., push mechanism; and (2) Other firms may develop relationships with a nondominant firm if they find that the nondominant firm has implemented IBPS, i.e., pull mechanism (Zmud 1984). Based on this discussion, we theorize:

Proposition 2 (P2). Nondominant firms are likely to have a greater assimilation of IBPS if IBPS are perceived to help sustain relational specificity (P2a) and provide relationship extendability (P2b).

3.4.2. Influence Mechanisms. We expect that because of their involvement in standards-development consortia (Jacobs 2000), dominant firms will face strong normative pressure to adopt and deploy IBPS and serve as a role model for other firms (see also Teo et al. 2003). The normative pressure will play a role in IBPS assimilation in dominant firms in two ways. First, many dominant firms are members of IBPS development consortia (Jacobs 2000). Hence, these firms have a direct influence in the development process and specifications of IBPS. Decision makers of these firms may develop a shared perception that because of their direct involvement in the development process, IBPS will have a greater fit with their existing interorganizational routines. Such a shared mental model is a driving force of normative pressure (DiMaggio and Powell 1983). Second, decision makers in dominant firms may perceive that other members of the consortia and industry may expect them to implement IBPS first because of their market position and resource availability. Consequently, these firms will commit to adopting and deploying IBPS. For example, the top management of dominant firms (e.g., Intel and Cisco) is committed to deploying RosettaNet PIPs because of normative pressures resulting from their membership in RosettaNet. Therefore, we propose:

Proposition 3 (P3). Dominant firms are likely to have a greater assimilation of IBPS if there is a high normative pressure to assimilate IBPS.

We expect that all three influence mechanismscoercive, mimetic, and normative pressures-will play a role in IBPS assimilation in nondominant firms. Given that IBPS require mutual and synergistic adoption, dominant partners will exert coercive pressure by requiring their nondominant trading partners to implement a particular set of IBPS (e.g., Intel requires suppliers to implement a set of RosettaNet PIPs) or normative pressure by signaling their support to a particular IBPS in various ways, e.g., self-adoption, membership in a standards consortium, participation in standards-related conferences, and top management's communications in various public forums. Mimetic pressure can also be important if the key decision makers of nondominant firms perceive that other competing firms that have already implemented IBPS will capture market share through greater relational specificity with common dominant trading partners (e.g., Teo et al. 2003). Based on this discussion, we propose:

Proposition 4 (P4). Nondominant firms are likely to have a greater assimilation of IBPS if there is high coercive pressure $(\mathrm{P} 4 \mathrm{a})$, mimetic pressure $(\mathrm{P} 4 \mathrm{~b})$, and normative pressure $(\mathrm{P} 4 \mathrm{c})$ to assimilate IBPS.

3.4.3. Inertial Mechanisms. Inertial mechanisms (i.e., resource and routine rigidities) are major hurdles to IBPS assimilation for both dominant and nondominant firms. Even though dominant firms have greater resources than their nondominant counterparts (Sorescu et al. 2003), these firms may be unwilling to mobilize resources for IBPS assimilation because of factors such as culture, tradition, market success, and perceived performance lossknown sources of organizational inertia (Tushman and O'Reilly 1996). The refusal to invest in innovations that are perceived to disrupt current, successful organizational routines and status quo has been underscored in prior research (e.g., Gilbert 2005). In contrast, nondominant firms may be unable to obtain or deploy resources for IBPS assimilation because of the unavailability of resources. Some firms may not commit resources for IBPS assimilation due to organizational policies, lack of managerial championship, and/or negative feedback from important stakeholders. From a routine rigidity perspective, firms may face tremendous challenges associated with changing routines that may impede deployment of IBPS (Porter 2001, Nelson and Winter 1982). For both dominant 
and nondominant firms, greater assimilation of IBPS will depend on their ability and willingness to overcome organizational inertia.

Dominant firms have greater technological, financial, market-related resources, and unabsorbed (i.e., easily recoverable and redeployable) slack resources that can help overcome resource rigidity (e.g., Nohria and Gulati 1996, Sorescu et al. 2003). While routine rigidity will be a major concern for these firms due to their age and success in the market (Tushman and O'Reilly 1996), many of these firms have a proinnovation culture as evidenced by their willingness to join a standards-development consortium (Jacobs 2000). Such a culture may help overcome routine rigidity. These firms typically have the experience in managing work process changes and, therefore, will have the mechanisms in place to tackle challenges associated with such changes. These firms are likely to have the technological capabilities to integrate IBPS with internal processes and IT systems. Further, given greater availability of resources and financial strengths, these firms are more likely to overcome short-term productivity and performance losses due to the disruptions in organizational routines caused by IBPS implementation (Tushman and Romanelli 1985).

Nondominant firms are typically small and medium enterprises (SMEs) and decision makers may not be motivated to invest in innovations that do not lead to immediate gains in revenues and market share (Christensen and Bower 1996). These firms are more likely to get support in the form of technical know-how and training from their dominant counterparts. For example, Cisco and Intel provide technical support to their trading partners for implementing RosettaNet PIPs (Cartwright et al. 2005). Some standards-development consortia also provide the similar support (RosettaNet 2007). In some developing countries (e.g., Malaysia), the government provides financial support to SMEs to implement IBPS (RosettaNet 2007). Such external support may help nondominant firms overcome resource rigidity. Unlike dominant firms, nondominant firms do not typically have strong routine rigidity because these firms often have to maintain different interorganizational routines or processes for different dominant trading partners. Hence, we expect that these firms will be able to overcome routine rigidity during IBPS assimilation. Therefore, we theorize:
Proposition 5 (P5). Both dominant and nondominant firms are likely to have a greater assimilation of IBPS because of their ability and willingness to overcome resource and routine rigidities.

\section{Research Methodology}

We used a multiple case study methodology to validate the conceptual model and theoretical propositions. Consistent with the guidelines by Dubé and Paré (2003) and exemplars from IS research (e.g., Sherif et al. 2006), we followed the positivist perspective. Data analysis, which was both qualitative and quantitative, was guided by theoretical propositions (Yin 1994) and restricted to an a priori set of constructs in the conceptual model (Figure 1). Our unit of analysis is a firm. These firms were represented by key informants who were actively involved in the process of IBPS implementation.

\subsection{Research Sites}

We collected data from the clients of an IT solutions provider about implementation of RosettaNet PIPs. Founded in 1998, RosettaNet is a nonprofit consortium aimed at facilitating e-business in the high-tech industry, e.g., electronic components, semiconductor manufacturing, and telecommunications. RosettaNet was an appropriate setting for this study because it is one of the few industry consortia that is dedicated to collaborative PIP development and rapid deployment of process standards. By focusing on a single IBPS in a single industry, we were able to control for certain organizational (e.g., product, market) and environmental (e.g., regulatory environment) variables.

4.1.1. Case Site Selection. According to the guidelines of multiple case study research (e.g., Dubé and Paré 2003, Eisenhardt 1989) and exemplars (e.g., Sambamurthy and Zmud 1999), the selection of the research sites should be done so as to allow substantial variation in the core theoretical constructs. Given that our key theoretical construct is IBPS assimilation, we identified firms that were in various stages of assimilation during the time of data collection, thus providing variability across the stages. With the help of our source company, we interacted with 56 client firms that were evaluating RosettaNet PIPs for adoption or deployment. We selected 11 out of 
those 56 client firms for this study and grouped them into four categories: (1) nonadopters; (2) adopters (but no deployment yet); (3) limited deployment; and (4) general deployment. Within each category, we included both dominant and nondominant firms in their respective IORs.

Each firm's dominance was assessed using three key dimensions-market share, assets, and profits as suggested in prior research (see Chandy et al. 2003, Sorescu et al. 2003). We obtained the data from publicly available corporate documents or, in the absence of such documents, from the informants. As the firms had different business functions (e.g., manufacturer, distributor), we could not determine firm dominance based only on financial data. Therefore, we asked the informants the extent to which they believed that their firms were dominant in IORs and that their trading partners were dependent on them for revenues. In general, we found that large firms with greater market share, capitalization, and profits were dominant in their IORs and were major sources of revenues for their small and medium trading partners.

Limited and general deployment stages were assessed based on the number of related PIPs deployed by each firm. If a firm deployed at least three related PIPs to automate a complete value chain activity, e.g., "order to cash" with at least one of its trading partners, we considered the firm to be in the general deployment stage. This approach of operationalizing assimilation stages is consistent with prior research (e.g., Fichman 2001, Fichman and Kemerer 1997). Table 2 presents the organizational profiles.

\subsection{Data Collection}

Over a period of two years, we collected data using multiple approaches: semistructured interviews, documents provided by the IT departments and key informants, and other publicly available information (e.g., press releases, financial statements, and trade press articles). The key informants were identified in two complementary ways: (1) We asked client and project managers in our source firm to identify one or more key informants from the client firms who promoted and actively pursued implementation of RosettaNet PIPs; (2) We asked the same of a member of top management (e.g., CIOs, vice presidents) of each client firm. The key informants were middle managers (e.g., purchase manager, client manager) including IT managers in large organizations (e.g., where the supply-side logistics unit had its own IT staff). A total of 21 individuals were interviewed from the 11 firms. We started with a set of initial questions that we asked all key informants. Later questions were dictated by the responses. The interview protocol is provided in Appendix A. Most interviews were audiotaped. If the interviewee did not want to be taped, the interview was transcribed directly during the interview.

\subsection{Data Analysis}

We conducted both within-case and cross-case analyses. We iterated between qualitative and quantitative analyses to help us identify robust patterns in the data. Our data analysis approach was guided by the theoretical propositions (Yin 1994), with the coding of data being tied to the constructs in our model.

4.3.1. Within-Case Analysis. Within-case analysis was performed to understand the unique patterns of each case. The interview transcripts and other documents were first read by one of the authors who used a data reduction and presentation technique for analyzing, triangulating, and documenting the contents of the transcripts and documents (Krippendorff 1980, Miles and Huberman 1984) to identify relevant quotes and events representing the three theoretical mechanisms, i.e., relational, influence, and inertial. The entire coding process was repeated by an intern from our source firm. The coders compared their codes and no significant differences were identified. Minor disagreements were discussed and resolved. After this initial coding was completed, a finer grained coding was performed by the same coders where the data within each broad category were coded into constructs associated with the theoretical mechanisms. For example, quotes related to influence mechanisms were further classified into coercive, mimetic, or normative. Appendix B provides descriptions of the theoretical mechanisms, constructs, and associated codes.

The quantitative analysis included a content analysis of the interview data using the NUD*IST software. Nodes were created in the software to represent the coding categories identified in the process described above. The software provided counts of statements related to each of our theoretical mechanisms. These 
Table 2 Organizational Profile

\begin{tabular}{|c|c|c|c|c|}
\hline Site & Primary business function & Dominant & Description & Assimilation stage \\
\hline A & Hardware manufacturer & No & $\begin{array}{l}\text { Aware of RosettaNet; no formal evaluation or } \\
\text { trial conducted during data collection period. }\end{array}$ & Nonadopter \\
\hline B & Electronics component manufacturer & No & $\begin{array}{l}\text { Aware of RosettaNet; no formal evaluation or } \\
\text { trial conducted during data collection period. }\end{array}$ & \\
\hline $\mathrm{C}$ & Multi-industry distributor & Yes & $\begin{array}{l}\text { Aware of RosettaNet; formal evaluation conducted; } \\
\text { no trial during data collection. }\end{array}$ & \\
\hline $\mathrm{D}$ & Hardware manufacturer & No & $\begin{array}{l}\text { Adoption decision made following formal evaluation; } \\
\text { no trial; no PIPs were deployed. }\end{array}$ & Adopter (no deployment yet) \\
\hline $\mathrm{E}$ & Hardware manufacturer & Yes & $\begin{array}{l}\text { Adoption decision made following formal evaluation } \\
\text { and trial; no PIPs were deployed. }\end{array}$ & \\
\hline $\mathrm{F}$ & Software distribution center & No & 1 PIP deployed & Limited deployment \\
\hline G & Hardware distributor & No & 2 PIPs deployed & \\
\hline $\mathrm{H}$ & Healthcare instrument manufacturer & Yes & 2 PIPs deployed & \\
\hline I & Semiconductor components distributor & No & 6 PIPs deployed for order management process & General deployment \\
\hline $\mathrm{J}$ & Hardware manufacturer & Yes & 4 PIPs deployed for order management process & \\
\hline $\mathrm{K}$ & Hardware and semiconductor manufacturer & Yes & 6 PIPs deployed to automate order-to-cash process & \\
\hline
\end{tabular}

counts were totaled for dominant and nondominant firms within each category, i.e., nonadopters, adopters, limited deployment, and general deployment. We also calculated the average and proportion of coded comments for each category.

4.3.2. Cross-Case Analysis. A cross-case analysis was performed to understand the variations across the cases and to find alternative or novel explanations for the findings from the within-case analysis (Eisenhardt 1989, Yin 1994). Individual cases within each category (i.e., nonadopters, adopters, limited deployment, and general deployment) were first compared to each other to discover similarities and variations within each category. This step allowed us to develop a general pattern of findings within each category and plausible explanations for such findings. The patterns were then compared across the categories to glean similarities and differences of findings and to understand distinct mechanisms in each category.

\section{Results}

We used both quantitative and qualitative results to find support for our propositions. First, we assessed the average number of comments made by the informants that fit into one of our theoretical mechanisms. We also assessed the proportion of comments made by the informants to understand the mechanisms that are more important for a given category of firms. Second, we used interview quotes and organizational events related to IBPS implementation to find additional support for our propositions. Table 3 presents the quantitative coding across different assimilation stages for dominant and nondominant firms. It presents the average and proportions of comments made by the informants. In the event that a particular mechanism did not exist or was not important for a given category, the table shows a zero in the number of comments column. To find support for our propositions, we need to demonstrate that the pattern of comments made by the informants is consistent with the propositions. For example, if the relationship posited in P1a (dominant firms will have a greater assimilation of IBPS due to relational depth) is to hold, we need to demonstrate that the informants from the dominant firms that reached the general deployment stage had a higher proportion of comments related to relational depth than: (1) that of other relational mechanisms (i.e., relational specificity and relationship extendability); and (2) those of the informants from the dominant firms in the nonadoption, adoption, or limited deployment stages.

\subsection{Effects of Relational Mechanisms}

We theorized that relational depth and relationship extendability would be key relational mechanisms for greater IBPS assimilation in dominant firms (P1a and P1b). As shown in Table 3, the informants from 
Table 3 Construct Coding by Assimilation Stages

\begin{tabular}{|c|c|c|c|c|c|c|c|c|c|c|c|c|c|c|c|c|}
\hline \multirow{4}{*}{$\begin{array}{l}\text { Theoretical } \\
\text { mechanisms }\end{array}$} & \multicolumn{8}{|c|}{ Nonadopters } & \multicolumn{8}{|c|}{ Adopters } \\
\hline & \multicolumn{4}{|c|}{ Nondominant $(2 / 4)^{*}$} & \multicolumn{4}{|c|}{ Dominant $(1 / 2)^{*}$} & \multicolumn{4}{|c|}{ Nondominant $(1 / 2)^{*}$} & \multicolumn{4}{|c|}{ Dominant $(1 / 2)^{*}$} \\
\hline & \multirow{2}{*}{$\begin{array}{c}\text { No. of } \\
\text { comments }\end{array}$} & \multirow[b]{2}{*}{ Avg. $^{\dagger}$} & \multicolumn{2}{|c|}{ Proportion** } & \multirow{2}{*}{$\begin{array}{c}\text { No. of } \\
\text { comments }\end{array}$} & \multirow[b]{2}{*}{ Avg. $^{\dagger}$} & \multicolumn{2}{|c|}{ Proportion** } & \multirow{2}{*}{$\begin{array}{c}\text { No. of } \\
\text { comments }\end{array}$} & \multirow[b]{2}{*}{ Avg. $^{\dagger}$} & \multicolumn{2}{|c|}{ Proportion** } & \multirow{2}{*}{$\begin{array}{c}\text { No. of } \\
\text { comments }\end{array}$} & \multirow[b]{2}{*}{ Avg. $^{\dagger}$} & \multicolumn{2}{|c|}{ Proportion** } \\
\hline & & & 1 & 2 & & & 1 & 2 & & & 1 & 2 & & & 1 & 2 \\
\hline \multicolumn{17}{|c|}{ Relational mechanisms } \\
\hline Specificity & $0^{\ddagger}$ & - & - & - & $0^{\ddagger}$ & - & - & - & 17 & 17 & 0.52 & 0.22 & 1 & 1 & 0.04 & 0.02 \\
\hline Depth & $0^{\ddagger}$ & - & - & - & $0^{\ddagger}$ & - & - & - & 5 & 5 & 0.15 & 0.06 & 15 & 15 & 0.56 & 0.34 \\
\hline Extendability & $0^{\ddagger}$ & - & - & - & $0^{\ddagger}$ & - & - & - & 11 & 11 & 0.33 & 0.14 & 11 & 11 & 0.41 & 0.25 \\
\hline $\begin{array}{r}\text { Total (relational } \\
\text { mechanisms) }\end{array}$ & 0 & - & - & - & 0 & - & - & - & 33 & 33 & 1.00 & 0.42 & 27 & 27 & 1.00 & 0.61 \\
\hline \multicolumn{17}{|c|}{ Influence mechanisms } \\
\hline Coercive & $0^{\ddagger}$ & - & - & - & $0^{\ddagger}$ & - & - & - & 9 & 9 & 0.30 & 0.12 & 2 & 2 & 0.13 & 0.05 \\
\hline Mimetic & $0^{\ddagger}$ & - & - & - & $0^{\ddagger}$ & - & - & - & 11 & 11 & 0.37 & 0.14 & 2 & 2 & 0.13 & 0.05 \\
\hline Normative & $0^{\ddagger}$ & - & - & - & $0^{\ddagger}$ & - & - & - & 10 & 10 & 0.33 & 0.13 & 11 & 11 & 0.73 & 0.25 \\
\hline $\begin{array}{l}\text { Total (influence } \\
\text { mechanisms) }\end{array}$ & 0 & - & - & - & 0 & - & - & - & 30 & 30 & 1.00 & 0.38 & 15 & 15 & 1.00 & 0.34 \\
\hline \multicolumn{17}{|c|}{ Inertial mechanisms } \\
\hline Resource & 4 & 2 & 0.50 & 0.50 & 8 & 8 & 0.42 & 0.42 & 7 & 7 & 0.47 & 0.09 & $0^{\ddagger}$ & - & - & - \\
\hline Routine & 4 & 2 & 0.50 & 0.50 & 11 & 11 & 0.58 & 0.58 & 8 & 8 & 0.53 & 0.10 & 2 & 2 & 1.00 & 0.05 \\
\hline $\begin{array}{l}\text { Total (inertial } \\
\text { mechanisms) }\end{array}$ & 8 & 4 & 1.00 & 1.00 & 19 & 19 & 1.00 & 1.00 & 15 & 15 & 1.00 & 0.19 & 2 & 2 & 1.00 & 0.05 \\
\hline \multirow{3}{*}{$\begin{array}{l}\text { Total no. of } \\
\text { comments }\end{array}$} & 8 & 4 & & 1.00 & 19 & 19 & & 1.00 & 78 & 78 & & 1.00 & 44 & 44 & & 1.00 \\
\hline & & & & ieneral & ployment & & & & & & & mited d & ployment & & & \\
\hline & & dominan & $(1 / 2)^{*}$ & & & ominant & $2 / 4)^{*}$ & & Non & dominan & $(2 / 4)^{*}$ & & & minant & $1 / 1)^{*}$ & \\
\hline Relational mechan & & & & & & & & & & & & & & & & \\
\hline Specificity & 11 & 11 & 0.61 & 0.18 & 3 & 1.5 & 0.11 & 0.05 & $0^{\ddagger}$ & - & - & - & $0^{\ddagger}$ & - & - & - \\
\hline Depth & 3 & 3 & 0.17 & 0.05 & 11 & 5.5 & 0.41 & 0.19 & $0^{\ddagger}$ & - & - & - & $0^{\ddagger}$ & - & - & - \\
\hline Extendability & 4 & 4 & 0.22 & 0.07 & 13 & 6.5 & 0.48 & 0.23 & $0^{\ddagger}$ & - & - & - & $0^{\ddagger}$ & - & - & - \\
\hline $\begin{array}{l}\text { Total (relational } \\
\text { mechanisms) }\end{array}$ & 18 & 18 & 1.00 & 0.30 & 27 & 13.5 & 1.00 & 0.47 & 0 & - & - & - & 0 & - & - & - \\
\hline Influence mechani & & & & & & & & & & & & & & & & \\
\hline Coercive & 9 & 9 & 0.33 & 0.15 & 2 & 1 & 0.15 & 0.04 & $0^{\ddagger}$ & - & - & - & $0^{\ddagger}$ & - & - & - \\
\hline Mimetic & 10 & 10 & 0.37 & 0.16 & 2 & 1 & 0.15 & 0.04 & $0^{\ddagger}$ & - & - & - & $0^{\ddagger}$ & - & - & - \\
\hline Normative & 8 & 8 & 0.30 & 0.13 & 9 & 4.5 & 0.69 & 0.16 & $0^{\ddagger}$ & - & - & - & $0^{\ddagger}$ & - & - & - \\
\hline $\begin{array}{l}\text { Total (influence } \\
\text { mechanisms) }\end{array}$ & 27 & 27 & 1.00 & 0.44 & 13 & 6.5 & 1.00 & 0.23 & 0 & - & - & - & 0 & - & - & - \\
\hline Inertial mechanisn & & & & & & & & & & & & & & & & \\
\hline Resource & 7 & 7 & 0.44 & 0.11 & 8 & 4 & 0.47 & 0.14 & 11 & 5.5 & 0.52 & 0.52 & 5 & 5 & 0.56 & 0.56 \\
\hline Routine & 9 & 9 & 0.56 & 0.15 & 9 & 4.5 & 0.53 & 0.16 & 10 & 5 & 0.48 & 0.48 & 4 & 4 & 0.44 & 0.44 \\
\hline $\begin{array}{l}\text { Total (inertial } \\
\text { mechanisms) }\end{array}$ & 16 & 16 & 1.00 & 0.26 & 17 & 8.5 & 1.00 & 0.30 & 21 & 10.5 & 1.00 & 1.00 & 9 & 9 & 1.00 & 1.00 \\
\hline $\begin{array}{l}\text { Total no. of } \\
\text { comments }\end{array}$ & 61 & 61 & & 1.00 & 57 & 28.5 & & 1.00 & 21 & 10.5 & & 1.00 & 9 & 9 & & 1.00 \\
\hline
\end{tabular}

\footnotetext{
*The numbers represent the total number of firms and the total number of interviewees, respectively.

** Of the two columns under this header, the first column presents the proportion of comments within each theoretical mechanism (e.g., relational mechanisms, etc.) and the second column presents the proportion relative to the total comments within each category (e.g., nondominant nonadopters, dominant nonadopters, etc.).

${ }^{\dagger}$ Average relative to the number of firms.

${ }^{\ddagger} A$ comment where the informants noted that the particular factor did not exist or was not important (e.g., key informants from the nonadopting firms mentioned that relational and influence mechanisms were nonexistent or not important to them).
} 
the dominant adopter (Manufacturer E; see Table 2 for profiles) made more comments about relational depth $(56 \%$ of comments within relational mechanisms and $34 \%$ of total comments with a mean of 15 per firm) and relationship extendability ( $41 \%$ of comments within relational mechanisms and $25 \%$ of total comments with a mean of 11 per firm) than they made about relational specificity $(4 \%$ of comments within relational mechanisms and $2 \%$ of total comments with a mean of 1 per firm). Similarly, the informants from the dominant firms in the general deployment stage (Manufacturers J and K) made more comments about relational depth $(41 \%$ of comments within relational mechanisms and $19 \%$ of total comments with a mean of 5.5 per firm) and relationship extendability ( $48 \%$ of comments within relational mechanisms and 23\% of total comments with a mean of 6.5 per firm) than they made about relational specificity ( $11 \%$ of comments within relational mechanisms and $5 \%$ of total comments with a mean of 1.5 per firm).

While we expected that relational depth and relationship extendability would be more important for greater assimilation (i.e., general deployment), the results indicated that they were almost equally important for adoption and general deployment. We offer the following explanation for this finding. The informants from the dominant adopter (Manufacturer E) focused primarily on their reasons for adopting PIPs. As this firm did not deploy any PIPs during the time of data collection, it did not face any challenges associated with resource and routine rigidities. However, the informants from the dominant firms in the general deployment stage (Manufacturers J and K) noted how they overcame resource and routine rigidities during the deployment process, thus increasing the proportion of comments about inertial mechanisms. As a result, the proportion of comments on relational mechanisms did not increase as much as we expected for these firms. However, this finding is within the spirit of propositions ( $\mathrm{P} 1 \mathrm{a}$ and $\mathrm{P} 1 \mathrm{~b}$ ) that relational depth and relationship extendability are important for IBPS assimilation in dominant firms.

The informants from the dominant nonadopter (Distributor C) did not mention any relational benefits of adopting RosettaNet PIPs (see Table 3). Many of Distributor C's trading partners were small and medium manufacturers that supplied electronic components to other manufacturers through Distributor C. The informants believed that adoption of RosettaNet PIPs would not improve the extent of current relationship with these partners as they (the informants) did not envision any future collaborative initiatives (i.e., relational depth) outside the current supply chain activities. Further, they did not perceive that RosettaNet PIPs would help them expand their current partner base (i.e., relationship extendability). For instance, an informant in Distributor C noted, "We have perfected our interaction with all six of our strategic partners. Why change?" Table 3 shows that the relational mechanisms were not important considerations for the dominant firm in the limited deployment stage (Manufacturer $\mathrm{H}$ ) in deciding whether to deploy more PIPs. The informant from Manufacturer $\mathrm{H}$ noted that implementing additional PIPs would not help improve the current relationships (i.e., relational depth) or create new relationships (i.e., relationship extendability).

We theorized that, for nondominant firms, the salient relational mechanisms would be relational specificity (P2a) and relationship extendability (P2b). Table 3 shows that the informants of the nondominant firm that adopted IBPS (Manufacturer D) made more comments about relational specificity (52\% of comments within relational mechanisms and $22 \%$ of total comments with a mean of 17 per firm) and relationship extendability (33\% of comments within relational mechanisms and $14 \%$ of total comments with a mean of 11 per firm) than they made about relational depth (15\% of comments within relational mechanisms and $6 \%$ of total comments with a mean of 5 per firm). We found that relational specificity was the most important driver of IBPS assimilation for the nondominant firm (Distributor I) that reached the general deployment stage $(61 \%$ of comments within relational mechanisms and $18 \%$ of total comments). While we expected relationship extendability would be important for nondominant firms in the general deployment stage, we found that it was not as important as relational specificity (22\% of comments compared to $61 \%$ of comments within relational mechanisms).

Table 3 shows that relational mechanisms were not important for the nondominant firms in the nonadoption (Manufacturers A and B) and limited deployment 
stages (Distributors $\mathrm{F}$ and $\mathrm{G}$ ). While the informants from Manufacturers A and B noted the importance of relationship with important trading partners, they emphasized the lack of relational benefits of adopting PIPs. An informant from Manufacturer B noted, "Each of our partners has some idiosyncratic process on their side and we have figured it all out over the years. Changing now will be costly. We have far too few transactions and partners to make the learning worth it." This suggests that Manufacturer B developed unique knowledge about the business processes of their trading partners. Implementation of RosettaNet PIPs would put the firm in a position where this knowledge could not be effectively leveraged. The informants from Manufacturers A and B did not perceive any new collaborative initiatives (i.e., relational depth) or expansion of partnership (i.e., relationship extendability). Hence, relational mechanisms were not major drivers of IBPS adoption in these firms. We found similar results for the limited deployment firms (Distributors F and G). The informants did not mention any relational benefits from deploying more PIPs. An informant in Distributor G noted, "What we have done thus far hits the mark... . Adding any other PIPs is going to add no value to our partner relations."

Overall, we found that, consistent with proposition (P2a), relational specificity led to greater assimilation of IBPS in nondominant firms. While relationship extendability was important (P2b), it was not as important as relational specificity. This suggests that nondominant firms deployed more PIPs to maintain the existing relationships with trading partners, particularly dominant counterparts, rather than to leverage PIPs in other existing relationships or in creating new partnering relationships.

\subsection{Effects of Influence Mechanisms}

We theorized that normative pressure would be the key influence mechanism for greater IBPS assimilation in dominant firms (P3). As shown in Table 3, the informants of the dominant firm that adopted IBPS (Manufacturer E) made more comments about normative pressure $(73 \%$ of comments within influence mechanisms and $25 \%$ of total comments with a mean of 11 per firm) than they made about coercive or mimetic pressures $(13 \%$ of comments within influence mechanisms and $5 \%$ of total comments with a mean of 2 per firm). We also found a similar pattern of results for the dominant firms (Manufacturers $\mathrm{J}$ and $\mathrm{K}$ ) that reached the general deployment stage $(69 \%$ of comments within influence mechanisms and $16 \%$ of total comments with a mean of 4.5 per firm). While we expected that normative pressure would be more important for greater assimilation (i.e., general deployment) in dominant firms, we found that it was almost equally important for adoption and general deployment. As explained earlier, the informants from the dominant firms in the general deployment stage made comments about overcoming resource and routine rigidities (i.e., inertial mechanims), which in turn might have reduced the proportion of their comments on other mechanisms. Nevertheless, our findings are generally consistent with proposition (P3) that dominant firms will assimilate IBPS because of high normative pressure.

The informants from the dominant firms that did not adopt RosettaNet PIPs (Distributor C) or were stuck in the limited deployment stage (Manufacturer $\mathrm{H}$ ) noted that they did not feel any external pressure to adopt or deploy PIPs. The informants from Distributor $C$ mentioned that they did not face any pressure from their trading partners to adopt RosettaNet PIPs. Moreover, Distributor C was not a member of RosettaNet-hence, the informants did not feel much normative pressure to adopt RosettaNet PIPs. The informant from Manufacturer $\mathrm{H}$ also voiced a similar lack of external pressure to implement more PIPs. He noted that while some of the competitors and partners implemented more PIPs, they did not feel any pressure to implement more PIPs. He pointed out that the reasons for not implementing more PIPs are mostly internal (we discuss these reasons in §5.3).

We expected that all three influence mechanisms (i.e., coercive, mimetic, and normative) would play important roles in the assimilation of IBPS in nondominant firms ( $\mathrm{P} 4 \mathrm{a}, \mathrm{P} 4 \mathrm{~b}$, and $\mathrm{P} 4 \mathrm{c})$. The informants from the nondominant firms that were in the adoption (Manufacturer D) and general deployment stages (Distributor I) made a similar number of comments about coercive, mimetic, and normative pressures. While the informants of the nondominant firm in the general deployment stage (Distributor I) made more comments about influence mechanisms than did the informants from the nondominant firms in the 
nonadoption (Manufacturers A and B) and limited deployment stages (Distributors F and G), there was no difference in the pattern of comments on influence mechanisms between the nondominant firms in the adoption (Manufacturer D) and general deployment (Distributor I) stages. This suggests that all three influence mechanisms played equally important roles in the adoption and deployment decisions of the nondominant firms. Thus, we found support for propositions ( $\mathrm{P} 4 \mathrm{a}, \mathrm{P} 4 \mathrm{~b}$, and $\mathrm{P} 4 \mathrm{c}$ ) that influence mechanisms will play an important role in IBPS assimilation in nondominant firms.

The informants from the nondominant firms that did not adopt RosettaNet (Manufacturers A and B) or were stuck in the limited deployment stage (Distributors $F$ and $G$ ) noted that they did not feel any external pressures to adopt or deploy more PIPs. The informants from Manufacturers A and B mentioned that there was no pressure from their trading partners to adopt RosettaNet PIPs. The following quote from an informant in Manufacturer A illustrates the absence of influence mechanisms: "We don't make decisions. We follow the lead of our holding company and major partners... . Did the customer ask for this? I don't think so. We shouldn't do it until someone can prove it can enhance customer happiness with us."

An interesting contrast emerges in terms of quotes when examining Distributors $F$ and $G$ that were stuck in the limited deployment stage. Unlike Manufacturers A and B, Distributors F and G made no mention of the existence of external pressure or lack thereof. This led us to conclude that these firms faced no external pressures, quite likely contributing to their decision to stay in the limited deployment stage. In §5.3, we elaborate on the role of inertial mechanisms in a firm's decision to stay in the limited deployment stage.

\subsection{Effects of Inertial Mechanisms}

We theorized that both dominant and nondominant firms would have a greater assimilation of IBPS because of their ability and willingness to overcome resource and routine rigidities (P5). The informants from the dominant firm in the adoption stage (Manufacturer E) made very few comments about resource and routine rigidities relative to the number of comments about relational and influence mechanisms $(5 \%, 61 \%$, and $34 \%$ of total comments on inertial, relational, and influence mechanisms, respectively). We noticed, however, that the informants from the dominant firms that reached the general deployment stage (Manufacturers J and $\mathrm{K}$ ) made more comments on inertial mechanisms (30\% of total comments) than did informants from Manufacturer E. The informants from Manufacturers J and $\mathrm{K}$ explained the challenges they faced during the deployment of PIPs in terms of resources (e.g., IT staff, business process experts, IT integration) and routines (e.g., resistance from employees). They also mentioned about top management support and various initiatives to overcome these challenges. For example, extensive business process training (simulation- and game-based) and support programs were used by Manufacturer $\mathrm{K}$ to teach employees new processes and the fit of different PIPs to help combat employee resistance.

We found that the dominant firms that were in the nonadoption (Distributor C) and limited deployment stages (Manufacturer $\mathrm{H}$ ) were unable to overcome resource and routine rigidities. Corporate documents from these firms revealed a lack of managerial commitment of resources (e.g., training) to facilitate implementation of RosettaNet PIPs. Manufacturer $\mathrm{H}$ faced tremendous resistance from employees to implementing more PIPs. A quote illustrates the routine rigidity in Manufacturer $\mathrm{H}$ : "I fear that employee jobs would become mind numbing... No one ever thought about how boring it has made over $50 \%$ of the jobs in our company. It's a big battle now."

The findings related to the nondominant firms that did not adopt RosettaNet (Manufacturers A and B) or were stuck in the limited deployment stage (Distributors F and G) shed lights on the role of inertial mechanisms in IBPS assimilation. While relational and influence mechanisms were not important to these firms (see Table 3), inertial mechanisms played an inhibiting role in IBPS adoption and deployment. An informant from Manufacturer A noted, "We can't afford it. We are keen to see if the consortium will help us with free technology and training. Then, we can try."

The informants from the nondominant firms in the limited deployment stage (Distributors F and G) mentioned that they could not deploy more PIPs due to resource constraints. Corporate documents from Distributor $G$ indicated that a memo was sent to several trading partners to help provide training on the 
new processes and technology. Distributor F had significant resource rigidities as evidenced by top management's reluctance to provide additional resources (i.e., financial and human capital) after implementing just one PIP. While Distributor I, a nondominant firm that reached the general deployment stage, also had resource and routine rigidities as evidenced by the number of comments shown in Table 3, it was able to overcome these inertial forces with support from its top management and dominant trading partners who provided not only technical support but also training and on-site support.

Overall, we found, consistent with proposition (P5), that both dominant and nondominant firms were able to reach the general deployment stage because of their ability and/or willingness to overcome inertial mechanisms. We also found that while the dominant firms did not place much importance on inertial mechanisms when making the adoption decision, these firms faced challenges associated with resource and routine constraints during the deployment stages. Table 4 presents findings about inertial mechanisms. It suggests that the firms that did not adopt RosettaNet PIPs or were in the limited deployment stage were unable to overcome these rigidities (i.e., high proportion of comments under the "No" column). In contrast, the firms that adopted RosettaNet PIPs or reached the general deployment stage had a greater ability and/or willingness to overcome these rigidities.

\subsection{Interplays Among Mechanisms}

Some of the comments made by the informants suggested interesting interplays among the three mechanisms. Particularly, we noticed that the interplay between relational and influence mechanisms played an important role in IBPS assimilation for nondominant firms. For example, we found that the presence or absence of pressures from important partners influenced the informants to view the importance of relational specificity or lack thereof. In other words, strong pressure from a dominant trading partner may force the decision makers of a nondominant firm to evaluate the importance of relational specificity with this trading partner. If relational specificity is not important in this case, a nondominant firm may overlook the pressure from the dominant partners. The following quote from an informant in Manufacturer B, a nondominant firm, sheds light on the interplay between relational specificity and influence

Table 4 Overcoming Organizational Inertia

\begin{tabular}{|c|c|c|c|c|c|c|c|c|c|c|c|c|c|}
\hline \multirow[b]{3}{*}{$\begin{array}{l}\text { Assimilation } \\
\text { stages }\end{array}$} & \multirow[b]{3}{*}{$\begin{array}{c}\text { Firm } \\
\text { dominance }\end{array}$} & \multicolumn{6}{|c|}{$\begin{array}{l}\text { Resource rigidity } \\
\text { Overcame** }\end{array}$} & \multicolumn{6}{|c|}{$\begin{array}{l}\text { Routine rigidity } \\
\text { Overcame** }\end{array}$} \\
\hline & & \multicolumn{3}{|c|}{ Yes } & \multicolumn{3}{|c|}{ No } & \multicolumn{3}{|c|}{ Yes } & \multicolumn{3}{|c|}{ No } \\
\hline & & $\begin{array}{c}\text { No. of } \\
\text { comments }\end{array}$ & Avg. ${ }^{\dagger}$ & Proportion $\ddagger$ & $\begin{array}{c}\text { No. of } \\
\text { comments }\end{array}$ & Avg. $^{\dagger}$ & Proportion ${ }^{\ddagger}$ & $\begin{array}{c}\text { No. of } \\
\text { comments }\end{array}$ & Avg. ${ }^{\dagger}$ & Proportion $\neq$ & $\begin{array}{c}\text { No. of } \\
\text { comments }\end{array}$ & Avg. ${ }^{\dagger}$ & Proportion \\
\hline \multirow[t]{2}{*}{ Nonadopter $(3 / 6)^{*}$} & Nondominant $(2 / 4)^{*}$ & 0 & - & - & 4 & 2 & 1.00 & 0 & 一 & - & 4 & 2 & 1.00 \\
\hline & Dominant $(1 / 2)^{*}$ & 0 & - & - & 8 & 8 & 1.00 & 0 & - & - & 11 & 11 & 1.00 \\
\hline Total (nonadopter) & & 0 & - & & 12 & 4 & & 0 & - & & 15 & 5 & \\
\hline \multirow[t]{2}{*}{ Adopter $(2 / 4)^{*}$} & Nondominant $(1 / 2)^{*}$ & 5 & 5 & 0.71 & 2 & 2 & 0.29 & 6 & 6 & 0.75 & 2 & 2 & 0.25 \\
\hline & Dominant $(1 / 2)^{*}$ & 0 & - & - & 0 & - & - & 2 & 2 & 1.00 & 0 & - & - \\
\hline Total (adopter) & & 5 & 2.5 & & 2 & 1 & & 8 & 4 & & 2 & 1 & \\
\hline \multirow{2}{*}{$\begin{array}{l}\text { Limited } \\
\quad \text { deployment }(3 / 5)^{*}\end{array}$} & Nondominant $(2 / 4)^{*}$ & 4 & 2 & 0.36 & 7 & 3.5 & 0.64 & 3 & 1.5 & 0.30 & 7 & 3.5 & 0.70 \\
\hline & Dominant $(1 / 1)^{*}$ & 0 & - & - & 5 & 5 & 1.00 & 1 & 1 & 0.25 & 3 & 3 & 0.75 \\
\hline Total (limited deployment) & & 4 & 1.33 & & 12 & 4 & & 4 & 1.33 & & 10 & 3.33 & \\
\hline \multirow{2}{*}{$\begin{array}{l}\text { General } \\
\quad \text { deployment }(3 / 6)^{*}\end{array}$} & Nondominant $(1 / 2)^{*}$ & 5 & 5 & 0.71 & 2 & 2 & 0.29 & 7 & 7 & 0.78 & 2 & 2 & 0.22 \\
\hline & Dominant $(2 / 4)^{*}$ & 5 & 2.5 & 0.63 & 3 & 1.5 & 0.37 & 6 & 3 & 0.67 & 3 & 1.5 & 0.33 \\
\hline Total (general deployment) & & 10 & 3.33 & & 5 & 1.67 & & 13 & 4.33 & & 5 & 1.67 & \\
\hline
\end{tabular}

*The numbers represent the total number of firms and the total number of interviewees, respectively.

** Indicates whether an informant mentioned a firm's ability and/or willingness to overcome resource or routine rigidities. For firms in the limited and general deployment stages, it represents whether an informant mentioned if the firm was able to overcome resource or routine rigidities.

${ }^{\dagger}$ Average relative to the number of firms.

‡Proportion of comments relative to the total comments within a particular group (e.g., nonadopter dominant). 
mechanisms: "We will follow the lead of our strategic partners. Right now, there is no need to or no need to panic. Our partners are playing a wait-and-see game on RosettaNet. Some are thinking about betting the firm on a different standard. We will play along."

We also noticed an interplay between inertial and the other two mechanisms. The firms that were stuck in the limited deployment stage because of high resource and routine rigidities had no relational benefits from deploying more PIPs. Further, these firms did not face any institutional pressures to deploy more PIPs. This led us to believe that the lack of relational and/or influence mechanisms made the inertial mechanisms more salient to these firms. It is also possible that in the presence of high inertial mechanisms, relational and influence mechanisms receded to the background in the minds of the decision makers. Our findings indicate that firms are more likely to overcome high resource and routine rigidities in the presence of strong relational and/or influence mechanisms or vice versa. This further explains nondominant firms' willingness to overcome strong resource and routine rigidities. We found that the nondominant firm (Distributor I) that reached the general deployment stage overcoming inertial mechanisms had to deal with strong relational and influence mechanisms as noted by an informant: "We went with all related PIPs to better serve our major client... We are moving as fast as [name of the major client] dictates. We are high on number of PIPs relative even to Intel." This suggests that while resource and routine rigidities are major barriers to greater IBPS assimilation, the presence (or absence) of high degrees of relational and/or influence mechanisms enables decision makers to overcome these rigidities when making decisions about IBPS assimilation.

\section{Discussion}

The objective of this research was to understand the mechanisms of IBPS assimilation, i.e., the extent of deployment, in dominant and nondominant firms. We theorized that three key mechanisms (i.e., relational, influence, and inertial) would play differential roles in the assimilation of these standards in dominant and nondominant firms. Using rich qualitative data from case studies of 11 firms, we found support for our conceptual model and theoretical propositions.
Table 5 presents a summary of major findings. While extended enterprises were first created to facilitate cross-enterprise business transactions, in recent years firms involved in IORs have begun to explore and understand the strategic value of such relationships (Gulati 1998). Firms are seeking new ways to create, govern, measure, and make decisions about the extended enterprise. IBPS is one such way that can help firms realize the strategic benefits of a digitally enabled extended enterprise. Our findings suggest that implementation of IBPS may help both dominant and nondominant firms improve relational depth and extend relationships to more trading partners. Standardization of interorganizational linkages will help firms move from dyadic relationships that are subject to opportunistic behaviors (Williamson 1995) to true multilateral relationships in which firms will be able to exploit and explore business potential with trading partners.

\subsection{Theoretical Contributions and Implications}

We drew on three different theoretical perspectivesthe relational view of the firm (e.g., Dyer and Singh 1998), institutional theory (e.g., DiMaggio and Powell 1983), and organizational inertia theory (e.g., Tushman and O'Reilly 1996) - to understand the assimilation of IBPS in the context of IORs. Our research makes three key contributions. First, our findings highlight the distinct role of the three mechanisms (i.e., relational, influence, and inertial), suggesting that an isolated treatment of these mechanisms may provide an incomplete or even inaccurate picture of IBPS assimilation. Second, we extend innovation assimilation research (e.g., Purvis et al. 2001) by incorporating mechanisms pertinent to interorganizational contexts and providing a rich understanding of the role of organizational inertia in the assimilation process. Finally, we extend work on the adoption of IT standards (e.g., Zhu et al. 2006) by adding new drivers of standards assimilation. By using theoretical perspectives to examine IBPS assimilation, this work complements and extends prior work that explored various drivers of IBPS adoption (Venkatesh and Bala 2007).

This research contributes to the relational view of the firm (e.g., Dyer and Singh 1998) by adding and underscoring the importance of two constructs 


\begin{tabular}{|c|c|c|c|c|}
\hline \multirow[b]{2}{*}{ Firm type } & \multicolumn{4}{|c|}{ Assimilation stages } \\
\hline & Nonadopter & Adopter & General deployment & Limited deployment \\
\hline Nondominant & \multirow{2}{*}{$\begin{array}{l}\text { 1. Lack of relational benefits } \\
\text { (i.e., relational specificity, } \\
\text { relational depth, and } \\
\text { relationship extendability) } \\
\text { or institutional pressures } \\
\text { (i.e., coercive, mimetic, and } \\
\text { normative influences). } \\
\text { 2. Lack of top management } \\
\text { support and resource } \\
\text { availability (resource } \\
\text { rigidity) and potential } \\
\text { negative effect of process } \\
\text { changes (routine rigidity). }\end{array}$} & $\begin{array}{l}\text { Desire to maintain } \\
\text { relationships with dominant } \\
\text { partners (i.e., relational } \\
\text { specificity) and institutional } \\
\text { pressures (i.e., coercive, } \\
\text { mimetic, and normative). }\end{array}$ & $\begin{array}{l}\text { Despite high resource and } \\
\text { routine rigidities, these } \\
\text { firms reach the general } \\
\text { deployment stage to } \\
\text { maintain relationships with } \\
\text { dominant partners (i.e., } \\
\text { relational specificity) and } \\
\text { to comply with institutional } \\
\text { pressures (i.e., coercive, } \\
\text { mimetic, and normative). }\end{array}$ & \multirow{2}{*}{$\begin{array}{l}\text { 1. Lack of relational benefits } \\
\text { (i.e., relational specificity, } \\
\text { relational depth, and } \\
\text { relationship extendability) } \\
\text { and/or no institutional } \\
\text { pressures (i.e., coercive, } \\
\text { mimetic, and normative) to } \\
\text { widely deploy IBPS. } \\
\text { 2. High organizational inertia } \\
\text { (resource and routine } \\
\text { rigidities). }\end{array}$} \\
\hline Dominant & & $\begin{array}{l}\text { Gains (e.g., cost savings) } \\
\text { due to depth and breadth } \\
\text { of collaboration (i.e., } \\
\text { relational depth and } \\
\text { relationship extendability) } \\
\text { and normative pressures. }\end{array}$ & $\begin{array}{l}\text { Depth and breadth of } \\
\text { collaboration (i.e., relational } \\
\text { depth and relationship } \\
\text { extendability), normative } \\
\text { pressure, and ability and } \\
\text { willingness to overcome } \\
\text { resource and routine } \\
\text { rigidities. }\end{array}$ & \\
\hline
\end{tabular}

pertinent to the context of IBPS assimilation: relational depth and relationship extendability. While IBPS may reduce relational specificity for some firms when more firms adopt these standards, they will improve and extend IORs through relational depth (e.g., enhanced collaboration, cooperation, and knowledge sharing) and relationship extendability (e.g., ability to create new relationships). Prior research has suggested that a high degree of relational specificity (e.g., relationship-specific investments) may increase the threat of opportunism, particularly for firms that fear that their trading partners may switch to different partners and the relationship-specific investments will not provide expected returns (Williamson 1995). This suggests that firms will be more willing to assimilate IBPS to mitigate the threat of opportunism as IBPS are not relationship specific. Accordingly, nondominant firms will be more interested in assimilating IBPS as these firms are more vulnerable to opportunistic behaviors by their dominant counterparts. However, articles in the trade press and white papers and case studies from standards-development consortia such as RosettaNet suggest that dominant firms (e.g., Intel, Cisco) were the first to use IBPS in their relationships with their closest partners. This situation contradicts the findings from prior research as the threat of opportunism is negligible in these relationships, yet partners implemented IBPS. We believe that IBPS have unique features that are sources of different types of relational benefits, i.e., relational depth and relationship extendability, that are important rationale for both dominant and nondominant firms to invest in IBPS and make IBPS a part of the organizational business model. Our research extends prior research by underscoring these relational mechanisms pertinent to IBPS.

Consistent with institutional theory, we found that the predominant response to institutional pressures was acquiescence-following norms, mimicking, and obeying (see Oliver 1991). However, the specific mechanisms varied; particularly, some dominant firms experienced only normative pressure because of their membership in the RosettaNet consortium while nondominant firms experienced strong coercive, mimetic, and normative pressures. In some cases, these pressures did not result in greater assimilation of IBPS because of high resource and routine rigidities. Thus, we extend the work of Teo et al. (2003) who investigated institutional pressures in the context of IOS adoption by indicating that institutional pressures may vary between dominant and nondominant firms in IORs and that these pressures 
may not lead to investments in interorganizational assets in the presence of high organizational inertia.

This research contributes to the literature and theories of organizational inertia by examining the role of resource and routine rigidities in the context of IBPS assimilation. Much prior research has suggested that large firms have strong organizational inertia (i.e., resource and routine rigidities) due to various factors such as size, complexity, history, values, and norms (Tushman and O'Reilly 1996). However, we found that large (dominant) firms in general had much greater ability and willingness to overcome organizational inertia (i.e., resource and routine rigidities). Supporting our finding is Sorescu et al. (2003) who found that dominant firms implemented more radical innovations than did nondominant firms. In the high-tech industry where innovation is a norm and adoption of technology standards is a common practice, it is possible that the large firms are more open toward implementing IBPS.

\subsection{Practical Implications}

Our findings have important practical implications. First, our findings related to firms not adopting IBPS and not reaching the general deployment stage should alert industry leaders, executives, and members of standards-development consortia about the potential causes and remedies of such an undesirable situation. As we noted at the outset, more than $60 \%$ of firms still conduct interorganizational transactions through manual processes (e.g., phone, fax, e-mail) and disconnected IT systems (e.g., spreadsheet), resulting in process inefficiency and suboptimal performance (see Wailgum 2006). Assimilation of IBPS such as RosettaNet PIPs will be critical for firm performance in those industries (e.g., telecommunication) that faced significant financial challenges due to global economic sluggishness in recent years. Our results indicated that high resource and routine rigidities coupled with a lack of relational and influence mechanisms were the inhibiting forces behind low adoption and deployment of IBPS. Industry leaders and standards-development consortia should identify ways to reduce routine and resource rigidities. Some of our suggestions include providing financial and technical support and incentives to SMEs, developing training curricula, and organizing professional and educational programs (e.g., seminars, workshops, symposiums) to demonstrate the benefits of IBPS implementation. These programs will not only serve as a source of normative influence for both dominant and nondominant firms but also make the firms aware of potential inhibiting forces of greater IBPS assimilation.

Second, managers should be aware that implementation of IBPS is resource intensive and may require substantial changes to existing work processes, structures, and linkages among the core activities of a firm. Our results indicated that the ability and willingness of both dominant and nondominant firms to mobilize resources and change existing business processes during IBPS implementation are important to avoid being stuck in the limited deployment stage. Managers of dominant firms need to understand that IBPS assimilation requires a concerted effort by them and their trading partners, and unless nondominant partners adopt and implement IBPS, there is no true benefit from IBPS assimilation. Therefore, they may consider providing technical and financial support to nondominant partners for greater assimilation of IBPS. Managers of nondominant firms need to carefully consider the relational benefits of IBPS and institutional pressures exerted by dominant partners and other key industry players to adopt and implement IBPS. In addition, they should not be reluctant to seek support from dominant partners and standards-development consortia to avoid potential problems of resource and routine rigidities.

Finally, our findings have important implications for IT vendors that provide IBPS solutions. These organizations can develop different promotional strategies for dominant and nondominant firms as these firms have different motivations for IBPS assimilation. IT vendors can develop a relationship with standardsdevelopment consortia and industry leaders as these organizations have the ability to exert pressures on both dominant and nondominant firms. In addition, IT vendors can promote the features of IBPS that are sources of key benefits such as relational depth and relationship extendability.

\subsection{Limitations and Future Research Directions}

Our findings should be construed in light of the limitations of the research. First, the research was conducted in one industry setting (i.e., high-tech 
industry) and in the context of a particular IBPS (i.e., RosettaNet). While such an approach helped us control for various situational factors such as industry characteristics, product type, market characteristics, and technological competence, it is possible that these situational characteristics will play an important role in the assimilation of IBPS. Therefore, the role of potential contingencies and the generalizability of our findings to other industries and standards should be examined in future research. Second, we were unable to collect dyadic data that could have provided greater insights as assimilation of IBPS is essentially a mutual and synergistic activity. A related limitation is that we were unable to focus on network effects (i.e., the influence of mass adoption) as we did not have network- and/or industry-level data. Further, we only interviewed a small group of key informants from each firm. While we interviewed at least two informants per firm (except Manufacturer $\mathrm{H}$ ) to avoid single-informant bias, it is possible that the informants did not accurately reflect on a firm's relationship with other trading partner, actual institutional pressures, or the magnitude of organizational inertia. Other important stakeholders such as top management, members of the IT department, and employees should be the focus of future inquiry. Future researchers could use survey-based research methodology and collect dyadic data to provide insights on the relative importance of the determinants of IBPS assimilation to trading partners. Also, industry-level data can be collected to understand network effects in this context. Third, it is possible that researchers' own bias may confound the coding process. To mitigate such bias, we used a coder who was not part of the research team. Moreover, our codes are consistent with a large body of prior research from where we derived theoretical mechanisms (e.g., Dyer and Singh 1998, Gilbert 2005, Teo et al. 2003). Finally, a small number of case sites were selected for this study. However, we have considerable variations among the sites in terms of their roles in the supply chain, dominance, and extent of IBPS assimilation to ensure generalizability and robustness of our findings.

An important research direction is investigation of IBPS assimilation from a multiple contingencies perspective (Sambamurthy and Zmud 1999). Sambamurthy and Zmud suggested that firms' IT governance decisions are influenced by the interactions of salient contingency forces such as reinforcing, conflicting, and dominating contingencies. For example, firms facing dominating contingencies are forced to overlook other contingencies that may be present in the environment. In the context of IBPS assimilation, it is possible that some firms may face different contingency forces (e.g., technological, organizational, and environmental) which may interact with the determinants of IBPS assimilation and amplify or weaken the effects of these determinants on IBPS assimilation. Therefore, a fruitful future research direction would be to examine the influence of these contingencies on the decision to assimilate IBPS. Other theoretical perspectives-i.e., transaction cost economics theory (e.g., Williamson 1995), diffusion of innovation theory (e.g., Rogers 1995), and interorganizational network theories (e.g., Gulati 1998)—can be used to extend and enrich the research model proposed in this study. Finally, a logical extension of this work would be to examine the impact of IBPS assimilation on firm performance. Firms implement IBPS to improve IOR and gain relational and other benefits (i.e., cost savings, competitive advantage). Without such benefits, greater assimilation of IBPS may not have any value to key stakeholders (i.e., top management). Therefore, an important focus for future research should be on outcomes of IBPS assimilation.

\section{Conclusions}

While firms deploy complex technologies (e.g., supply chain systems, EDI) to improve IORs, a lack of process integration and automation prohibits the realization of benefits of such technologies. IBPS can create better IORs among trading partners. Our objective was to understand the assimilation of these standards in dominant and nondominant firms. Our findings suggest that while firms may adopt IBPS because of relational benefits and institutional pressures, they may be unable to reach the general deployment stage due to inertial mechanisms, i.e., resource and routine rigidities. We also found an interplay among the mechanisms. Our findings have important implications in today's global economy in which firms are increasingly relying on strategic IORs to create unique value for their customers and maximize stakeholders' 
benefits. We hope this work will fuel further research on IBPS.

\section{Acknowledgments}

The authors thank Senior Editor Dr. Robert Zmud for his guidance and support throughout the review process, Senior Editor Dr. Arun Rai, and Dr. V. Sambamurthy for their comments and feedback on various versions of the paper. The authors also thank three anonymous reviewers and participants in the ISR special issue workshop held at the University of Michigan for their many useful comments and suggestions that helped improve this paper. This paper also benefited from comments received from workshop attendees at the University of Arizona, University of California, Riverside, Michigan State University, City University of Hong Kong, and the University of WisconsinMilwaukee.

\section{Appendix A. Interview Protocol}

As noted in the paper, key informants were identified in two ways: (1) Client and project managers in our source firm identified one or more key informants from the client firms who promoted and actively pursued implementation of RosettaNet PIPs; (2) A member of top management (e.g., CIOs, vice presidents) of each client firm also identified the same. We selected the individuals who were common to both lists. If there were no common individuals, all identified individuals were interviewed. While we used a semistructured interview protocol, some questions were asked of all participants. Additional questions were asked based on the response. Examples of additional questions are provided (marked with ${ }^{*}$ ).

1. Describe your primary job function in the organization.

2. Do you typically recommend or make decisions about adoption of new technologies or other innovations for your business unit (department) and/or organization?*

3. Describe your current processes to share information and perform transactions with your trading partners.

4. Are you familiar with interorganizational business process standards?
5. When did you first hear about RosettaNet?

6. Are you familiar with RosettaNet? If so, can you tell me briefly what it aims to do?*

7. Do you use any standard technologies (e.g., EDI) to share information and perform transactions with your trading partners?*

8. Describe your existing technologies to share information and perform transactions with your trading partners.*

9. Have you already implemented any RosettaNet PIPs?

10. When did your organization first decide to implement RosettaNet PIPs?*

11. When was the first PIP implemented?*

12. Describe your organization's current plan for implementation of RosettaNet PIPs.

13. Have you done [do you plan to do] trial implementation of RosettaNet PIPs?*

14. Why do you [did you] think your organization should adopt [or not adopt] RosettaNet process standards?

15. What factors do you [did you] consider in deciding in favor of or against RosettaNet process standards?

16. How do you plan to convince [how did you convince] the key stakeholders (e.g., top management, potential executors of the business processes, and IT people) in favor of/against RosettaNet process standards?

17. How many PIPs have already been implemented at your organization?*

18. Why did you [or did you not] implement subsequent PIPs which are related to the PIPs that you already implemented?*

19. How did you decide about which PIP or PIPs to implement?*

20. Describe the training and support program at your organization for RosettaNet PIPs.*

21. Describe any challenges associated with RosettaNet implementation at your organization.*

22. Can you indicate when you might adopt the next PIP?*

23. How were the factors influencing the implementation of the latest PIP different from the previous PIP you implemented?*

\section{Appendix B. Description of Coded Concepts}

\begin{tabular}{|c|c|c|c|}
\hline Mechanisms & Constructs & Description & Codes (key words) \\
\hline $\begin{array}{l}\text { Relational } \\
\text { mechanisms }\end{array}$ & $\begin{array}{l}\text { Relational } \\
\text { specificity }\end{array}$ & $\begin{array}{l}\text { Development of and willingness to } \\
\text { sustain a unique relationship } \\
\text { with a particular trading partner. }\end{array}$ & $\begin{array}{l}\text {-Importance of relationship } \\
\text { - Length of relationship } \\
\text { - Investment in relationship specific resources } \\
\text { - Product uniqueness (only a particular trading } \\
\text { partner buys/sells these products) } \\
\text { - Customized and integrated interorganizational } \\
\text { assets and routines shared by trading partners } \\
\text { - Understanding of trading partners' interorganizational } \\
\text { processes }\end{array}$ \\
\hline
\end{tabular}


Appendix B. (cont'd.)

\begin{tabular}{|c|c|c|c|}
\hline Mechanisms & Constructs & Description & Codes (key words) \\
\hline \multirow[t]{2}{*}{$\begin{array}{l}\text { Relational } \\
\text { mechanism }\end{array}$} & Relational depth & $\begin{array}{l}\text { Ability and willingness of a firm to find } \\
\text { new avenues to collaborate with existing } \\
\text { trading partners. }\end{array}$ & $\begin{array}{l}\text {-Extent of communication and coordination } \\
\text { - Knowledge of trading partners' capabilities (e.g., } \\
\text { technological) for greater collaboration } \\
\text { - Collaborative initiatives in other value chain activities } \\
\text { - Increasing knowledge sharing with trading partners }\end{array}$ \\
\hline & $\begin{array}{l}\text { Relationship } \\
\text { extendability }\end{array}$ & $\begin{array}{l}\text { Ability and willingness of a firm to redeploy } \\
\text { and leverage existing relation-specific assets } \\
\text { or routines in other relationships or to } \\
\text { develop new relationships. }\end{array}$ & $\begin{array}{l}\text {-Opportunity for new relationships } \\
\text { - More trading partners } \\
\text { - Partnering flexibility (e.g., ability to change partners) } \\
\text {-Economies of scale in using IBPS }\end{array}$ \\
\hline \multirow[t]{3}{*}{$\begin{array}{l}\text { Influence } \\
\text { mechanisms }\end{array}$} & $\begin{array}{l}\text { Coercive } \\
\text { pressure }\end{array}$ & $\begin{array}{l}\text { Pressure from other firms on which a focal } \\
\text { firm is dependent and pressure to conform } \\
\text { to societal expectations. }\end{array}$ & $\begin{array}{l}\text { - Trading partners' pressures } \\
\text { - Conformity with parent organization's policy } \\
\text { - Resource and revenue dependence } \\
\text { - Switching cost }\end{array}$ \\
\hline & $\begin{array}{l}\text { Mimetic } \\
\text { pressure }\end{array}$ & $\begin{array}{l}\text { Pressure to imitate the actions of structurally } \\
\text { equivalent successful organizations (peers } \\
\text { or competitors) in the same industry. }\end{array}$ & $\begin{array}{l}\text { - Success of adoption by competitors } \\
\text { - Profitability of competitors } \\
\text { - Trading partners prefer competitors } \\
\text { - Competitors get discounts from RosettaNet } \\
\text { - Competitors get favors from trading partners }\end{array}$ \\
\hline & $\begin{array}{r}\text { Normative } \\
\text { pressure }\end{array}$ & $\begin{array}{l}\text { Pressure to conform to industry norms } \\
\text { developed through relationships and } \\
\text { professional and trade associations. }\end{array}$ & $\begin{array}{l}\text {-Extent of adoption/implementation by trading } \\
\text { partners and competitors } \\
\text { - Membership of RosettaNet } \\
\text { - RosettaNet promotions } \\
\text { - Industry and trade seminars and conferences }\end{array}$ \\
\hline \multirow[t]{2}{*}{$\begin{array}{l}\text { Inertial } \\
\text { mechanisms }\end{array}$} & $\begin{array}{r}\text { Resource } \\
\text { rigidity }\end{array}$ & $\begin{array}{l}\text { Inability or failure to change resource } \\
\text { investment patterns and commitment in } \\
\text { response to external threats or } \\
\text { opportunities. }\end{array}$ & $\begin{array}{l}\text { - Resource commitment (e.g., investment } \\
\text { size/availability of financial resources) } \\
\text {-Top management support } \\
\text { - Corporate strategy alignment } \\
\text { - Conformity with parent company's policy } \\
\text { - Training/workshop/conference facilities } \\
\text { - Technology readiness (e.g., IT competence) }\end{array}$ \\
\hline & $\begin{array}{l}\text { Routine } \\
\text { rigidity }\end{array}$ & $\begin{array}{l}\text { Inability or failure to change organizational } \\
\text { routines and/or work processes in } \\
\text { response to external threats or opportunities. }\end{array}$ & $\begin{array}{l}\text {-Employee support } \\
\text { - Resistance to change to existing business processes } \\
\text {-Organizational culture (e.g., receptiveness to innovation) } \\
\text { - Job-related changes (e.g., reduced responsibilities, } \\
\text { deskilling, relationship changes) } \\
\text {-Ease of implementation and learning of the changed } \\
\text { business processes } \\
\text {-Presence of old and/or parallel processes }\end{array}$ \\
\hline
\end{tabular}

\section{References}

Barringer, B. R., J. S. Harrison. 2000. Walking a tightrope: Creating value through interorganizational relationships. J. Management 26(3) 367-403.

Barua, A., P. Konana, A. B. Whinston, F. Yin. 2004. Assessing netenabled business value: An exploratory analysis. MIS Quart. 28(4) 585-620.

Bensaou, M. 1999. Portfolio of buyer-supplier relationships. Sloan Management Rev. 40(4) 35-44.

Bensaou, M., E. Anderson. 1999. Buyer-supplier relations in industrial markets: When do buyers risk making idiosyncratic investments? Organ. Sci. 10(4) 460-481.

Cartwright, J., J. Hahn-Steichen, J. He, T. Miller. 2005. RosettaNet for Intel's trading entity automation. Intel Tech. J. 9(3) 239-246.

Chabrow, E., L. Sullivan. 2004. Billions to save. InformationWeek (July 12)
Chandy, R. K., J. P. Prabhu, K. D. Antia. 2003. What will the future bring? Dominance, technology expectations, and radical innovation. J. Marketing 67(3) 1-18.

Choudhury, V. 1997. Strategic choices in development of interorganizational information systems. Inform. Systems Res. 8(1) $1-24$.

Christensen, C. M., J. L. Bower. 1996. Customer power, strategic investment, and the failure of leading firms. Strategic Management J. 17 197-218.

Chwelos, P., I. Benbasat, A. S. Dexter. 2001. Research report: Empirical test of an EDI adoption model. Inform. Systems Res. 12(3) 305-321.

Corsten, D., N. Kumar. 2005. Do suppliers benefit from collaborative relationships with large retailers? An empirical investigation of efficient consumer response adoption. J. Marketing 69(3) 80-94. 
Damodaran, S. 2005. RosettaNet: Adoption brings new problems, new solutions. XML 2005 Conf. Exhibition Proc., IDE Alliance, Alexandria, VA, 1-14.

David, P. A., S. Greenstein. 1990. The economics of compatibility standards: An introduction to recent research. Econom. Innovations New Tech. 1(1/2) 3-41.

David, P. A., W. E. Steinmueller. 1994. Economics of compatibility standards and competition in telecommunication networks. Inform. Econom. Policy 6 217-241.

DiMaggio, P., W. W. Powell. 1983. The iron cage revisited: Institutional isomorphism and collective rationality in organizational fields. Amer. Sociol. Rev. 48(2) 147-160.

Dubé, L., G. Paré. 2003. Rigor in information systems positivist case research: Current practices, trends, and recommendations. MIS Quart. 27(4) 597-636.

Dyer, J. H., H. Singh. 1998. The relational view: Cooperative strategy and sources of interorganizational competitive advantage. Acad. Management Rev. 23(4) 660-679.

Eisenhardt, K. 1989. Building theories from case study research. Acad. Management Rev. 14(4) 532-550.

Feldman, M. S., B. T. Pentland. 2003. Reconceptualizing organizational routines as a source of flexibility and change. Admin. Sci. Quart. 48 94-118.

Fichman, R. G. 2001. The role of aggregation in the measurement of IT-related organizational innovation. MIS Quart. 25(4) 201-429.

Fichman, R. G., C. F. Kemerer. 1997. The assimilation of software process innovations: An organizational learning perspective. Management Sci. 43(11) 1345-1363.

Fichman, R. G., C. F. Kemerer. 1999. The illusory diffusion of innovation: An examination of assimilation gaps. Inform. Systems Res. 10(3) 255-275.

Gilbert, C. G. 2005. Unbundling the structure of inertia: Resource vs. routine rigidity. Acad. Management J. 48(5) 741-763.

Gosain, S., A. Malhotra, O. A. El Sawy. 2004-2005. Coordinating for flexibility in e-business supply chains. J. Management Inform. Systems 21(3) 7-46.

Gosain, S., A. Malhotra, O. A. El Sawy, F. Chehade. 2003. Towards frictionless e-Business: The impact of common electronic business interfaces. Comm. ACM 46(12) 186-195.

Gulati, R. 1998. Alliances and networks. Strategic Management J. 19(4) 293-317.

Hart, P., C. Saunders. 1997. Power and trust: Critical factors in the adoption and use of electronic data interchange. Organ. Sci. 8(1) 23-42.

Henderson, R. M., K. G. Clark. 1990. Architectural innovation: Reconfiguration of existing product technologies and the failure of established firms. Admin. Sci. Quart. 35(1) 61-82.

Jakcobs, K. 2000. Standardization Processes in IT-Impact, Problems and Benefits of User Participation. Vieweg Publishers, Wiesbaden, Germany.

Jap, S. D., S. Ganesan. 2000. Control mechanisms and the relationship life cycle: Implications for safeguarding specific investments and developing commitment. J. Marketing Res. 37(May) 227-245.

Karpinski, R. 2001. Cisco attempts to boost B-to-B sales. InternetWeek (March 16).

Krippendorff, K. 1980. Content Analysis: An Introduction to Its Methodology. Sage Publications, Beverly Hills, CA.

Levinthal, D. 1992. Surviving Schumpeterian environments: An evolutionary perspective. Indust. Corporate Change 1 427-443.
Levinthal, D. A., J. G. March. 1993. The myopia of learning. Strategic Management J. 14 95-112.

Madhok, A., S. B. Tallman. 1998. Resources, transactions and rents: Managing value through interfirm collaborative relationships. Organ. Sci. 9(3) 326-339.

Magretta, J. 2002. Why business models matter. Harvard Bus. Rev. 80(5) 3-8.

Malhotra, A., S. Gosain, O. A. El Sawy. 2005. Absorptive capacity configurations in supply chains: Gearing for partner-enabled market knowledge creation. MIS Quart. 29(1) 145-187.

Markus, M. L., C. W. Steinfield, R. T. Wigand, G. Minton. 2006. Industry-wide information systems standardization as collective action: The case of the U.S. residential mortgage industry. MIS Quart. 30(Special Issue) 439-465.

Miles, M. B., A. M. Huberman. 1984. Qualitative Data Analysis: A Sourcebook of New Methods. Sage Publications, Newbury Park, CA.

Mukhopadhyay, T., S. Kekre, S. Kalathur. 1995. Business value of information technology: A study of electronic data interchange. MIS Quart. 19(2) 137-157.

Nelson, M., M. Shaw, W. Qualls. 2005. Interorganizational system standards development in vertical industries. Electronic Markets 15(4) 378-392.

Nelson, R., S. Winter. 1982. An Evolutionary Theory of Economic Change. Harvard University Press, Cambridge, MA.

Nohria, N., R. Gulati. 1996. Is slack good or bad for innovation? Acad. Management J. 39(5) 1245-1264.

Oliver, C. 1991. Strategic responses to institutional processes. Acad. Management Rev. 16(1) 145-179.

Oliver, C. 1997. Sustainable competitive advantage: Combining institutional and resource-based views. Strategic Management J. 18(9) 697-713.

Pfeffer, J., G. R. Salancik. 1978. The External Control of Organizations. Harper \& Row, New York.

Porter, P. 2001. Deciphering RosettaNet. CIO Insight (July 1).

Premkumar, G., K. Ramamurthy, N. Sree. 1994. Implementation of electronic data interchange: An innovation diffusion perspective. J. Management Inform. Systems 11(2) 157-186.

Purvis, R. L., V. Sambamurthy, R. W. Zmud. 2001. The assimilation of knowledge platforms in organizations: An empirical investigation. Organ. Sci. 12(2) 117-135.

Rai, A., R. Patnayakuni, N. Patnayakuni. 2006. Firm performance impacts of digitally enabled supply chain integration capabilities. MIS Quart. 30(2) 225-246.

Riggins, F. J., C. H. Kriebel, T. Mukhopadhyay. 1994. The growth of interorganizational systems in the presence of network externalities. Management Sci. 40(8) 894-998.

Rogers, E. 1995. Diffusion of Innovations. Free Press, New York.

Rokkan, A. I., J. B. Heide, K. H. Wathne. 2003. Specific investments in marketing relationships: Expropriation and bonding effects. J. Marketing Res. 40(May) 210-224.

RosettaNet. 2007. www.rosettanet.org.

Sambamurthy, V., R. W. Zmud. 1999. Arrangements for information technology governance: A theory of multiple contingencies. MIS Quart. 23(2) 261-290.

Sambamurthy, V., A. Bharadwaj, V. Grover. 2003. Shaping agility through digital options: Reconceptualizing the role of it in contemporary firms. MIS Quart. 27(2) 237-263. 
Sherif, K., R. W. Zmud, G. J. Brown. 2006. Managing peer-to-peer conflicts in disruptive information technology innovations: The case of software reuse. MIS Quart. 30(2) 339-356.

Sorescu, A. B., R. K. Chandy, J. C. Prabhu. 2003. Sources and financial consequences of radical innovation: Insights from pharmaceuticals. J. Marketing 67(4) 82-102.

Subramani, M. 2004. How do suppliers benefit from information technology use in supply chain relationships? MIS Quart. 28(1) $45-73$.

Sullivan, L. 2004. Supply-chain inefficiencies exact huge toll. InformationWeek (July 12).

Teece, D. J., G. Pisano, A. Shuen. 1997. Dynamic capabilities and strategy management. Strategic Management J. 18(7) 509-553.

Teo, H. H., K. K. Wei, I. Benbasat. 2003. Predicting intention to adopt interorganizational linkages: An institutional perspective. MIS Quart. 27(1) 19-49.

Tushman, M. L., C. O'Reilly. 1996. Ambidextrous organizations: Managing evolutionary and revolutionary change. California Management Rev. 38(4) 8-30.

Tushman, M. L., E. Romanelli. 1985. Organizational evolution. L. L. Cummings, B. M. Staw, eds. Research in Organizational Behaviour. JAI Press, Greenwich, CT, 171-222.

Venkatesh, V., H. Bala. 2007. Adoption of interorganizational business process standards in business-to-business integration: An exploratory study. Systemes d'Information et Management 12(2) 53-78.

Wailgum, T. 2006. Supply chain management: Integration liberation. CIO Magazine (October 15).
Webster, J. 1995. Networks of collaboration or conflict? Electronic data interchange and power in the supply chain. J. Strategic Inform. Systems 4(1) 31-42.

Whiting, R. 2003. What drives business-technology innovation? Look to large companies' supply chains, not just tech vendors. InformationWeek (August 4).

Wigand, R. T., C. W. Steinfield, M. L. Markus. 2005. Information technology standards choices and industry structure outcomes: The case of the U.S. home mortgage industry. J. Management Inform. Systems 22(2) 165-192.

Williamson, O. E. 1995. Transaction cost economics and organization theory. O. E. Williamson, ed. Organization Theory: From Chester Barnard to the Present and Beyond. Oxford University Press, New York.

Yin, R. K. 1994. Case Study Research: Design and Methods, 2nd ed. Sage Publications, Newbury Park, CA.

Zhao, K., M. Xia, M. Shaw. 2005. Vertical e-business standards and standards developing organizations: A conceptual framework. Electronic Markets 15(4) 289-300.

Zhu, K., K. L. Kraemer, V. Gurbaxani, S. Xu. 2006. Migration to open-standard interorganizational systems: Network effects, switching costs, and path dependency. MIS Quart. 30(Special Issue) 515-539.

Zmud, R. 1984. An examination of "push-pull" theory applied to process innovation in knowledge work. Management Sci. 30(6) 727-738.

Zollo, M., J. J. Reuer, H. Singh. 2002. Interorganizational routines and performance in strategic alliances. Organ. Sci. 13(6) 701-713. 